\title{
Studi Eksperimental Pengaruh Bilangan Reynold dan Fraksi Massa Terhadap Koefisien Perpindahan Panas Konveksi pada Pipa Coil
}

\author{
Firman Iskandarsyah ${ }^{1}$, Adek Tasri ${ }^{2}$, Rahmadian Pratama ${ }^{3}$ \\ ${ }^{1,2}$ Program Studi Teknik Mesin, Program Pascasarjana \\ ${ }^{3}$ Program Studi Teknik Mesin \\ Universitas Andalas Padang \\ E-mail : firman_smkn3jambi@yahoo.com, adek_tasri@ft.unand.ac.id, Rahmadian Pratama \\ @ gmail.com
}

\begin{abstract}
Abstrak
Aliran dua fase merupakan bagian dari aliran multi-fase dan masih dapat dibedakan menjadi beberapa bagian yang memepengaruhi koefisien perpindahan panas. Pada dunia industri, koefisien perpindahan panas memiliki arti penting. Dalam aplikasinya seperti pada proses pemanasan dan pendinginan, koefisien perpindahan panas sangat berpengaruh pada proses ini karena sangat menentukan hasil proses yang di inginkan.. Perubahan fasa ini menciptakan kondisi aliran dua fasa dimana sebelumnya aliran tersebut hanya satu fasa. Kondisi aliran dua fasa ini tentu memiliki koefisien perpindahan panas yang berbeda daripada aliran satu fasa. Sehingga kita perlu mengetahui besarnya pengaruh koefisien perpindahan panas pada aliran dua fasa. Penelitian ini bertujuan untuk menentukan pengaruh fraksi massa terhadap koefisien perpindahan panas pada dinding coil.
\end{abstract}

Kata kunci : koefisien perpindahan panas, perubahan fasa, kondisi aliran dua fasa, penukar kalor.

\section{Pendahuluan}

Peningkatan perpindahan panas pada peralatan penukar panas sering ditemui terjadi pada fluida yang terlibat pada perpindahan panas. Berbagai metode telah dikembangkan untuk meningkatkan efektifitas penukar kalor dengan jalan meningkatkan koefisien perpindahan kalor. Salah satu metode yang telah lama diaplikasikan sebagai penukar kalor adalah pipa koil helik atau helical coil tube. Penggunaan helical coil tube selain dapat mengurangi panjang dari penukar kalor juga dapat meningkatkan efektifitas penukar kalor. Ini dikarenakan ketika fluida mengalir dalam lintasan pipa yang berbentuk kurva, gaya sentrifugal menyebabkan terjadinya aliran sekunder. Aliran sekunder yang disebabkan oleh gaya sentrifugal ini memiliki kemampuan yang signifikan untuk meningkatkan laju perpindahan kalor. Beberapa penelitian telah menunjukkan bahwa helical coil tubes lebih unggul dibandingkan straight tubes bila digunakan dalam aplikasi transfer panas. Pemanfaatan alat penukar panas, jenis koil heliks vertical merupakan salah satu alat perpindahan panas yang banyak digunakan.
Koil heliks vertikal berupa sebuah pipa yang dibuat dengan bentuk melingkar (spiral) dimana diantara lingkaran satu dengan yang lainnya memiliki jarak tertentu (pitch).

Dalam dunia industri Koil heliks juga temukan dalam berbagai aplikasi. Misalnya pada sistem perpipaan, pada boiler, pada pembangkit tenaga nuklir, pada industri perminyakan dan lain sebagainya. Banyak penelitian yang telah dilakukan yang berhubungan alat penukar panas tipe heliks ini. K. Hambraeus [1] meneliti tentang koefisien perpindahan panas dua fasa dengan konveksi didih pada HFC134a mendapatkan penyimpangan koefisien perpindahan panas yang sangat kecil dan peningkatan penurunan tekanan secara linear. Mohamed El-Sayed Ali [2] menulis perpindahan panas konveksi secara alami pada helik dengan fluida minyak, menunjukan terjadinya penurunan koefisien pindahan panas seiring perubahan diameter helikdan jenis aliran didapat laminar. D. Colorado dkk [3] melakukan analisa perpindahan panas dan perilaku dinamis fluida dari double-pipa evaporator arah vertikal pada heliks secara numerical dan menghasilkan perbandingan data eksperimen dan data 
simulasi memperlihatkan deviasi fluks panas rata-rata $0,45 \%$. D. Colorado dkk [4] dapat menggambarkan perpindahan panas dari kumparan heliks dalam oli dan gliserol secara numeric dan menemukan peningkatan perpindahan panas. Harith Noori Mohammed [5] melakukan penelitian konveksi bebas pada penukar kalor tipe heliks posisi vertical dan menemukan koefisien perpindahan panas meningkat berbanding lurus terhadap peningkatan cairan pendinginnya.M.A. Khairul dkk [6] menganalisa perpindahan panas dan termodinamika dari penukar panas heliks menggunakan berbagai jenis nanofluids dan menemukan peningkatan efisiensi exergi yang lebih tinggi dengan menyuntikan nanopartikel. Xiande Fang [7] dalam penelitiannya mendapatkan korelasi yang lebih baik untuk $\mathrm{R} 134 \mathrm{a}$ untuk perpindahan panas aliran dua fase. N. Jamshidi dkk [8] melakukan analisis eksperimental peningkatan perpindahan panas di shell dan tube pada penukar panas tipe heliks menemukan dapat meningkatkan koefisien perpindahan panas keseluruhan secara optimum, merubah laju aliran dalam helik, diameter coil, laju aliran merupakan parameter desain yang paling penting dalam penukar panas. Srbislav B dkk [9] melakukan analisa fouling pada penukar panas helik dengan melakukan Pengukuran performa panas dan tidak menemukan fouling factor pada beberapa percobaan. José Fernández-Seara dkk [10] dalam kajian numerikal terhadap unjuk kerja helik secara ekperimental memprediksi perpindahan panas pada penukar kalor tipe heliks secara numeric dan mendapatkan hasil peningatan perpindahan panas seiring peningkatan diameter luar heliks. B.K. Hardik dkk [11] meneliti koefisien perpindahan panas lokal pada gulungan heliks dengan aliran fase tunggal dan mendapatkan pengaruh kelengkungan berbanding lurus terhadap nomor nusseltnya. Behrad Bezyan dkk [12] menganalisis kinerja termal pipa dengan Spiral berbentuk vertical secara simulasi 3D dan menyimpulkan konfigurasi diameter pipa berpengaruh terhadap panasnya. Sudhakar.Battu, V.Sridevi [13] mengulas perpindahan panas paksa melalui kumparan heliks dan menyimpulkan perpindahan panas pada heliks lebih tinggi dari tabung biasa. Xiaojuan Niu dkk [14] dengan analisa numeric tentang karakteristik aliran panas dalam tabung dengan pemanasan yang berbeda menemukan koefisien Perpindahan panas lokal di sekitar penampang tabung spiral melingkar dipengaruhi oleh kondisi pemanasan yang berbeda. Fabio Bozzoli dkk [15] meneliti efek pengerutan dinding pada heliks penukar kalor secara pendekatan analisis inverse dan menyimpulkan pengaruh yang siknifikan terhadap koefisien perpindahan panasnya.

Dari beberapa penelitian perpindahan panas yang ada berkaitan dengan koil heliks, untuk aliran dua fasa sampai saat ini belum banyak yang meneliti. Penelitian penentuan klasifikasinya sangat rumit Disamping dari fasenya aliran dua fase juga dibedakan berdasar arah aliran (searah dan berlawanan arah) dan kedudukan salurannya (tegak, mendatar, atau miring). Berdasarkan klasifikasi tersebut akan membedakan phenomena koefisien perpindahan panas pada aliran fluida dua fasa dalam pipa, Perubahan fasa dari cair menjadi campuran cair dan gas terutama akan menyebabkan perubahan sifat fisik fluida terutama nilai konduktivitas, viskositas, dan massa jenis fluida. Perubahan pada ketiga sifat tersebut menyebabkan perubahan koefisien perpindahan panas yang dapat digunakan sebagai dasar pengembangan model, Pengaruh aliran dua fasa pada heliks terhadap koofisien perpindahan panas tersebut coba diteliti pada jurnal ini dilabor motor bakar jurusan mesin universitas andalas padang.

\section{Deskripsi alat Uji}

Gambar 1. Menunjukan skema alat uji. Sistim aliran alat uji merupakan sistim aliran terbuka dengan air berfungsi sebagai fluida kerja. Sistim ini terdiri dari 1 unit reservoir, ditambah satu unit pompa sentrifugal, katup bola, katup bypass, gelas Ukur, dan unit coil helik vertikal yang merupakan bagian dari yang di uji. Seluruh variable yang diukur langsung pada saat penelitian nilainya bisa diketahui tanpa perlu perhitungan lebih lanjut Pada unit pengujian.

Air yang dipanaskan sampai temperatur $100^{\circ} \mathrm{C}$ dengan Pemanas pada reservoir 1 dialirkan menggunakan sebuah pompa sentrifugal, mengalir masuk ke katub bola untuk mengetahui laju alirannya. Katub bola sebagai pedoman pengatur laju aliran 6 liter/menit dilakukan secara manual. Dari Katub bola aliran air memasuki helik. Pada helik inilah divariasikan temperatur diding helik Daya listrik yang terukur tergantung variasi temparatur yang diberikan dengan tegangan 220 volt pada pemanas.

Termokopel dipasang dan digunakan untuk mengukur temperatur masuk dan keluar dari instrumen uji. Delapan belas termokopel digunakan untuk mengukur suhu. Termokopel pertama dipasang pada saluran keluar reservoir pertama, termokopel kedua dipasang pada saluran masuk coil helik, termokopel ketiga 
dipasang saluran keluaran helik dan lima belas termokopel berikutnya dipasang pada lima titik pengujian A,B,C,D dan E pada alat yang di uji. Semua instrumen (termokopel) terhubung ke Portabel data logger Zr-rx20 mempunyai 10 port, dimana semua hubungan terbaca pada data logger tersebut. Pembacaan dan pengambilan data dilakukan setelah mencapai kondisi stabil.

\section{Methodologi}

\subsection{Bahan dan Metode}

Gambar 2 kumparan heliks lurus digunakan untuk pengujian terbuat dari $70 \% \mathrm{Cu}$ dan $30 \%$ $\mathrm{Zn}$ dengan konduktivitas termal sebesar $111 \mathrm{~W} / \mathrm{m}^{\circ} \mathrm{C}$. Diameter pipa heliks $=0.00635 \mathrm{~m}$, panjang coil $0.8 \mathrm{~m}$, diameter kumparan $0.08 \mathrm{~m}$ dengan 2,5 lingkaran kumparan Ketebalan tabung semua kumparan heliks $0,25 \mathrm{~mm}$.
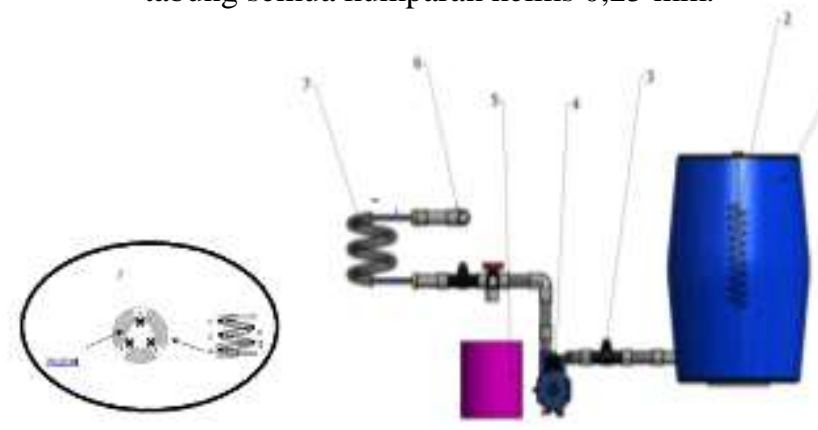

Gambar 1. Skema Sistem Instalasi Pengujian dan detail pengujian

Komponen tersebut adalah sebagai berikut:

1. Tangki / Wadah

2. Pemanas Listrik

3. Katub

4. Pompa

5. Gelas Ukur

6. Selang Keluaran

7. Koil Pengujian (Koil Heliks)

8. Dual Element Heating Tape

9. Isolasi Heater

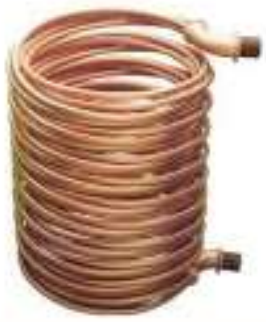

Gambar 2. Coil Helik

2.2 Data Reduksi

Bilangan Reynold (Re)
Bilangan Reynold untuk kumparan heliks dan tabung lurus dihitung dengan persamaan :

$$
R e=\frac{V D \rho}{\mu}=\frac{V d}{\mu}
$$

bilangan Reynolds dari aliran laminar ke turbulen aliran dihitung dari

$R e_{\pi}=20000\left(\frac{d}{D}\right)^{0,32}$ Mengacu persamaan ito

[16]

Bilangan Nusselt

Perbedaan suhu air yang diukur untuk menghitung perpindahan panas dari coil ke air pada beban panas yang diberikan dan kemudian dibagi dengan luas permukaan kumparan untuk menentukan fluks panas seperti yang ditunjukkan pada pada persamaan (3).

$$
q^{\prime \prime}=\frac{Q \operatorname{conv}}{A}
$$

Kehilangan panas karena konveksi dan radiasi di atmosfer dihitung dengan mengurangi panas yang disuplai ke kumparan heliks dan panas yang disuplai air. Dalam semua percobaan, kehilangan panas ke atmosfer ditemukan menjadi kurang dari 6\%.[11]. Koefisien perpindahan panas lokal dan nomor Nusselt lokal untuk permukaan dihitung dengan

$$
h_{\text {lokal }}=\frac{q^{\prime \prime}}{T_{\text {wlokal }}-T_{\text {blokal }}}
$$

Nilai kualitas fasa (x) didapatkan

$x=\frac{\left(U_{i n}+Q\right)-U_{f}}{U_{f g}}$

\section{Hasil dan Pembahasan}

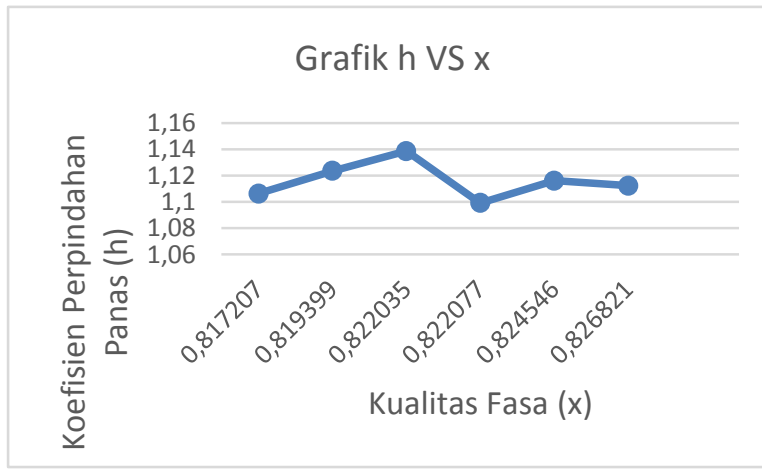

Gambar 3. Grafik Koefisien Perpindahan Panas vs Kualitas Fasa $(\mathrm{x})=0.2$

Gambar 3, 4, 5, dan 6 pada grafik terlihat bahwa nilai koefisien perpindahan panas fluida 
berwujud dua fasa cenderung berfluktuasi disekitar nilai rata-rata dengan variasi nilai kualitas uap. Pada penelitian ini, nilai rata-rata tersebut sebesar $1,0846 \mathrm{~kW} / \mathrm{m}^{2} .{ }^{o} \mathrm{C}$.

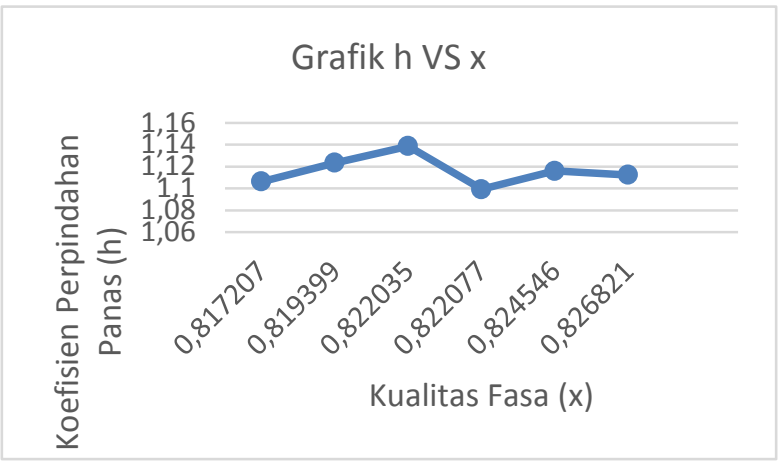

Gambar 4. Grafik Koefisien Perpindahan Panas vs Kualitas Fasa $(\mathrm{x})=0.4$

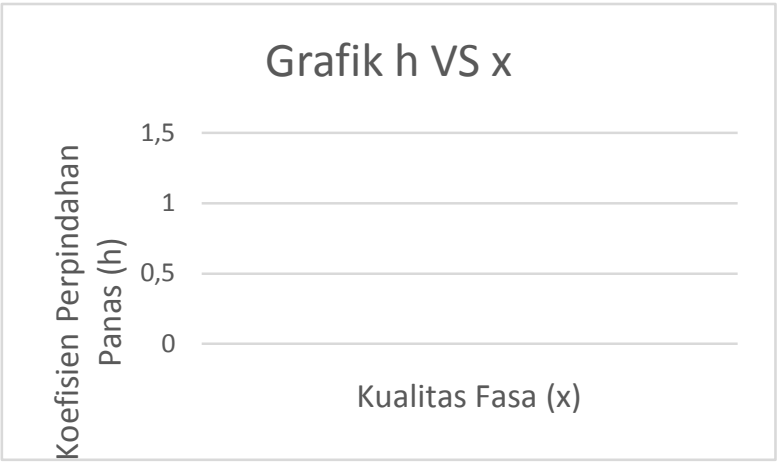

Gambar 5. Grafik Koefisien Perpindahan Panas vs Kualitas Fasa $(\mathrm{x})=0.6$

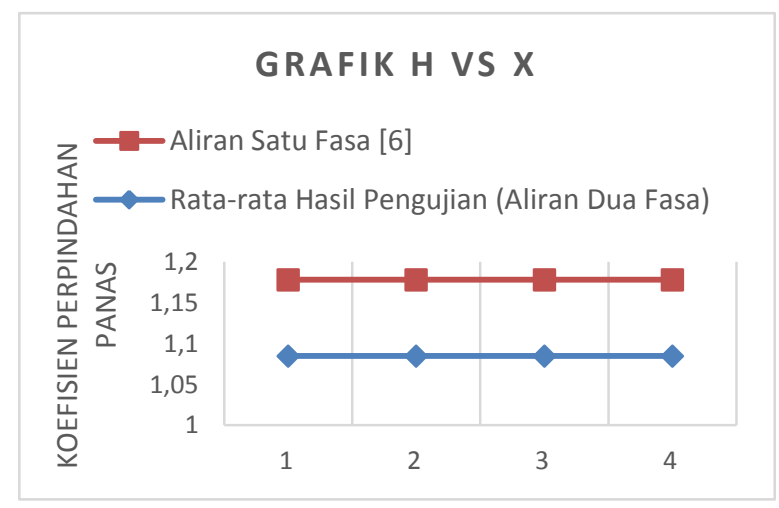

Gambar 7. Grafik Koefisien Perpindahan Panas vs Kualitas Fasa $(\mathrm{x})=0.8$

Penelitian ini juga membandingkan dengan koefisien perpindahan panas fluida satu fasa (berwujud cair). Hasil perbandingan yaitu nilai koefisien perpindahan panas fluida berwujud cair lebih tinggi daripada nilai koefisien perpindahan panas fluida berwujud campuran cair dan uap yaitu sebesar $1,178 \mathrm{~kW} / \mathrm{m}^{2} .{ }^{\circ} \mathrm{C}$. Terlihat pada grafik, 7 koefisien perpindahan panas fluida berwujud campuran cair dan uap mengalami penurunan sekitar $8 \%$ dari koefisien perpindahan panas fluida berwujud cair. Hal ini sesuai dengan teori yaitu perpindahan panas yang memiliki massa cair lebih banyak akan lebih tinggi dikarenakan perpindahan panas terjadi dengan gesekan antar molekul saat pergerakan molekul yang bersirkulasi. Kerapatan molekul juga termasuk salah satu faktor koefisien perpindahan panas. Fluida cair memiliki kerapatan molekul yang lebih rapat dibandingkan dengan gas sehingga proses perpindahan panas akan lebih cepat dan lebih baik.

\section{Simpulan}

Telah dilakukan pengujian yang dilakukan untuk mengetahui bagaimana pengaruh koefisien perpindahan panas terhadap nilai kualitas fasa yang berwujud dua fasa. Dari pengukuran ini dapat disimpulkan sebagai berikut :

1. Koefisien perpindahan panas terhadap variasi $\mathrm{x}$ berfluktuasi di sekitar nilai ratarata sebesar $1,0846 \mathrm{~kW} / \mathrm{m}^{2} \cdot{ }^{o} \mathrm{C}$

2. Dari data disimpulkan bahwa koefisien perpindahan panas tidak dipengaruhi secara signifikan oleh nilai kualitas fasa. Pada Kualitas fasa gaya pendorongnya perbedaan konsentrasi massanya, sedangkan transfer panas pendorongnya perbedaan suhu.

\section{Daftar Notasi}

\section{Simbol Deskripsi}

Satuan

$\mathrm{Cp}$ specific heat at constant pressure

$\mathrm{kJ} / \mathrm{kg} \mathrm{K}$

d diameter pipa

$\mathrm{mm}$

d/D curvature ratio

D diameter of coil

$\mathrm{mm}$

$\mathrm{D} / \mathrm{d} \quad$ coil rasio diameter coil

fc friction factor coil

fs Gaya gesek pada pipa

h koefisien perpindahan panas W/m2 K

k Konduktivitas termal W/m K 


$\begin{array}{lll}\mathrm{L}, & \text { Panjang } & \mathrm{mm} \\ \mathrm{m}_{-} & \text {Massa Aliran } & \mathrm{kg} / \mathrm{s} \\ \mathrm{l} & \text { Viscositas dinamik } & \mathrm{Pa} \mathrm{s} \\ \mathrm{p} & \text { Tinggi coil } & \mathrm{mm} \\ \mathrm{Q} & \text { Panas Masuk } & \mathrm{kW} \\ \mathrm{q} 00 & \text { Aliran Panas } & \mathrm{kW} / \mathrm{m} 2 \\ \mathrm{R}, \mathrm{r} & \text { radius } & \mathrm{mm} \\ \mathrm{q} & \text { Densitas } & \mathrm{kg} / \mathrm{m} 3 \\ \mathrm{~T} & \text { temperature } & { }^{0} \mathrm{C} \\ \mathrm{t} & \text { Tinggi } & \mathrm{mm} \\ \mathrm{x}, \mathrm{z} & \text { Panjang Lokal } & \mathrm{mm}\end{array}$

\section{Daftar Pustaka}

[1] K. Hambraeus, "Heat Transfer Coefficient , Two-Phase Flow Boiling of HFC134a," 1990.

[2] Mohamed El-Sayed Ali, "Natural Convection Heat Transfer from Vertical Helical Coils in Oil," ResearchGate, vol. 27, 2006.

[3] D. Colorado-Garrido, "Numerical simulation for the heat transfer of a helical double-pipe vertical evaporator," Proc. Eur. Congr. Chem. Eng. Copenhagen, no. September, pp. 16-20, 2007.

[4] D. Colorado-Garrido, "Heat transfer using a correlation by neural network for natural convection from vertical helical coil in oil and glycerol / water solution," Energy, vol. 36, 2011.

[5] H. N. Mohammed and A. Lecturer, "Experimental Study of Free Convection in Coiled Tube Heat Exchanger with Vertical Orientation," Tikrit J. Eng. Sci., vol. 18, no. 4, 2011.

[6] M.A. Khairul, "International Journal of Heat and Mass Transfer Heat transfer and thermodynamic analyses of a helically coiled heat exchanger using different types of nanofluids," Int. J. Heat Mass Transf., vol. 67, pp. 398-403, 2013.

[7] X. Fang, "International Journal of Heat and Mass Transfer A new correlation of flow boiling heat transfer coefficients based on R134a data," Int. J. Heat Mass
Transf., vol. 66, pp. 279-283, 2013.

[8] N. Jamshidi, M. Farhadi, D. D. Ganji, and K. Sedighi, "Experimental analysis of heat transfer enhancement in shell and helical tube heat exchangers," Appl. Therm. Eng., vol. 51, no. 1-2, pp. 644-652, 2013.

[9] S. B, "International Journal of Heat and Mass Transfer Analysis of fouling factor in district heating heat exchangers with parallel helical tube coils," Int. J. Heat Mass Transf., vol. 57, pp. 9-15, 2013.

[10] J. Fernández-seara, C. Piñeiro-pontevedra, and J. A. Dopazo, "On the performance of a vertical helical coil heat exchanger . Numerical model and experimental validation," Appl. Therm. Eng., vol. 62, no. 2, pp. 680-689, 2014.

[11] B. K. Hardik, P. K. Baburajan, and S. V Prabhu, "International Journal of Heat and Mass Transfer Local heat transfer coefficient in helical coils with single phase flow," Int. J. Heat Mass Transf., vol. 89, pp. 522-538, 2015.

[12] B. Bezyan, S. Porkhial, and A. Aboui, "3D simulation of heat transfer rate in geothermal pile-foundation heat exchangers with spiral pipe con fi guration," Appl. Therm. Eng., vol. 87, pp. 655-668, 2015.

[13] S. Battu, "A Brief Review on Forced Convection Through Helical Coil Heat Exchangers," Int. J. Innov. Res. Sci. Technol., vol. 2, no. 12, pp. 178-181, 2016.

[14] X. Niu, S. Luo, L. Fan, and L. Zhao, "Numerical simulation on the flow and heat transfer characteristics in the one-side heating helically coiled tubes," Appl. Therm. Eng., vol. 106, pp. 579-587, 2016.

[15] F. Bozzoli, L. Cattani, and S. Rainieri, "International Journal of Heat and Mass Transfer Effect of wall corrugation on local convective heat transfer in coiled tubes," Int. J. Heat Mass Transf., vol. 101, pp. 76-90, 2016.

[16] H. Ito, Friction factors for turbulent flow in curved pipes, Trans. Am. Soc. Mech. Eng. D81 (1959) 123-134

[17] G.F.C. Rogers, Y.R. Mayhew, Heat transfer and pressure loss in helically 
coiled tubes with turbulent flow, Int. J. Heat Mass Transfer 7 (1964) 1207-1216

[18] A. Cioncolini, L. Santini, An experimental investigation regarding the laminar to turbulent flow transition in helically coiled pipes, Exp. Thermal Fluid Sci. 30 (2006) 367-380

[19] R. Gupta, R.K. Wanchoo, T.R.M.J. Ali, Laminar flow in helical coils: a parametric study, Ind. Eng. Chem. Res. 50 (2011) 1150-1157 [20] Choi. Kwang, Taek. Jong. Two-Phase Flow Boiling Heat Transfer of R-410A and R-134A in Horizontal Small Tubes. 2011

[21] Ilham. M. Penentuan Kombinasi Diameter Pipa, Diameter Koil Dan Laju Aliran Yang Menghasilkan Koefisien Perpindahan Panas Tertinggi Pada Penukar Panas Jenis Koil. 2016

[22] Hulwani. Zati. D. Efek Perubahan Bentuk Pipa Dari Pipa Lurus Menjadi Pipa Koil Terhadap Koefisien Perpindahan Panas Konveksi Dari Pipa Ke Lingkungan. 2016 